\title{
The drivers of avian haemosporidian prevalence in tropical lowland forest of New Guinea in three dimensions
}

\author{
Celia Vinagre-Izquierdo ${ }^{1}$, Kasun Bodawatta ${ }^{1}$, Krystof $\mathrm{Chmel}^{2}$, Justinn Renelies-Hamilton ${ }^{3}$, \\ Luda Paul ${ }^{4}$, Nick Bos ${ }^{3}$, Pavel Munclinger ${ }^{5}$, Michael Poulsen ${ }^{3}$, and Knud Andreas Jønsson ${ }^{1}$ \\ ${ }^{1}$ Natural History Museum of Denmark \\ ${ }^{2}$ University of South Bohemia in Ceske Budejovice \\ ${ }^{3}$ University of Copenhagen Faculty of Science \\ ${ }^{4}$ New Guinea Binatang Research Center \\ ${ }^{5}$ Charles University in Prague
}

June 29, 2021

\begin{abstract}
Haemosporidians are among the most common parasites in birds and often impact negatively host fitness and consequently can affect entire host populations. It is therefore important to determine what factors influence parasite prevalence, particularly if they are caused by anthropogenic activities. Here we explore the effect of temperature, forest cover, and proximity to anthropogenic disturbance on haemosporidian prevalence and host-parasite networks on a horizontal spatial scale, comparing four fragmented forest patches and five localities within a continuous forest in Papua New Guinea. We find that the majority of Haemosporidian infections are caused by the genus Haemoproteus and that avian-haemosporidian networks are more specialized in continuous forests. At the community level, only forest cover was negatively associated with Haemoproteus infections, while abiotic and anthropogenic effects on parasite prevalence differed between bird species. We further tested if prevalence and host-parasite networks differed between the canopy and the understorey (vertical stratification) and found significantly higher Haemoproteus prevalence levels in the canopy, and the opposite trend for Plasmodium prevalence. This implies that birds experience distinct parasite pressures depending on the stratum they inhabit, likely driven by differences in vector communities. These three-dimensional analyses of avian-haemosporidians at horizontal and vertical scales provides a deeper understanding of the environmental factors driving haemosporidian prevalence in tropical lowland forests of New Guinea. Collectively, our results suggest that the effect of abiotic variables on haemosporidian infections are species specific, and that factors influencing community-level infections are primarily driven by host community composition.
\end{abstract}

The drivers of avian haemosporidian prevalence in tropical lowland forest of New Guinea in three dimensions

Running title: Blood parasite infections in tropical birds

Celia Vinagre-Izquierdo ${ }^{1,2}$, Kasun H. Bodawatta ${ }^{1}$, Kryštof $\mathrm{Chmel}^{3,4}$, Justinn Renelies-Hamilton ${ }^{2}$, Luda Paul $^{5}$, Nick Bos ${ }^{2}$, Pavel Munclinger ${ }^{6}$, Michael Poulsen ${ }^{2}$ and Knud A. Jønsson ${ }^{1}$.

Affiliations:

${ }^{1}$ Natural History Museum of Denmark, University of Copenhagen, Copenhagen, Denmark.

${ }^{2}$ Section for Ecology and Evolution, Department of Biology, University of Copenhagen, Copenhagen, Denmark. 
${ }^{3}$ Department of Zoology, Faculty of Sciences, University of South Bohemia, Branišovská, České Budějovice, Czech Republic.

${ }^{4}$ Biology Centre, Czech Academy of Sciences, Branišovská, České Budějovice, Czech Republic.

${ }^{5}$ New Guinea Binatang Research Centre, Madang, Papua New Guinea

${ }^{6}$ Department of Zoology, Faculty of Science, Charles University, Prague, Czech Republic.

Corresponding author: Celia Vinagre-Izquierdo, Section for Ecology and Evolution, Department of Biology, University of Copenhagen, Denmark; Natural History Museum of Denmark, University of Copenhagen, Copenhagen, Denmark; email: celia.vinagre.izquierdo@gmail.com; phone: +45919782 65; +34 629256983

\begin{abstract}
Haemosporidians are among the most common parasites in birds and often impact negatively host fitness and consequently can affect entire host populations. It is therefore important to determine what factors influence parasite prevalence, particularly if they are caused by anthropogenic activities. Here we explore the effect of temperature, forest cover, and proximity to anthropogenic disturbance on haemosporidian prevalence and host-parasite networks on a horizontal spatial scale, comparing four fragmented forest patches and five localities within a continuous forest in Papua New Guinea. We find that the majority of Haemosporidian infections are caused by the genusHaemoproteus and that avian-haemosporidian networks are more specialized in continuous forests. At the community level, only forest cover was negatively associated with Haemoproteus infections, while abiotic and anthropogenic effects on parasite prevalence differed between bird species. We further tested if prevalence and host-parasite networks differed between the canopy and the understorey (vertical stratification) and found significantly higher Haemoproteusprevalence levels in the canopy, and the opposite trend forPlasmodium prevalence. This implies that birds experience distinct parasite pressures depending on the stratum they inhabit, likely driven by differences in vector communities. These three-dimensional analyses of avian-haemosporidians at horizontal and vertical scales provides a deeper understanding of the environmental factors driving haemosporidian prevalence in tropical lowland forests of New Guinea. Collectively, our results suggest that the effect of abiotic variables on haemosporidian infections are species specific, and that factors influencing community-level infections are primarily driven by host community composition.
\end{abstract}

\title{
Keywords
}

Forest cover, Haemoproteus, Host-parasite networks, NDVI,Plasmodium, vertical stratification

\section{Introduction}

Parasites are ubiquitous, diverse and play major ecological roles in terrestrial and aquatic ecosystems (García del Río, Castaño-Vázquez, \& Merino, 2020; Poulin, 1999), where they are a prominent selective force that influences fitness, distribution and evolution of hosts (Poulin, 1998). Haemosporidians (Phylum Apicomplexa) are blood parasites transmitted by dipteran vectors and are among the most common parasites in vertebrates (Soares, Latta, \& Ricklefs, 2017), including in birds (Hellgren, Pérez-Tris, \& Bensch, 2009; Valkiūnas, 2005). Infections in birds generally impact host fitness negatively (Atkinson, 2009; LaPointe, Atkinson, \& Samuel, 2012; Rivero \& Gandon, 2018) and the introduction of haemosporidians to naïve bird communities (for example on previously-isolated islands) can have dramatic consequences and even lead to population collapse or species extinction (Ewen, Bensch, Blackburn, Bonneadu \& Brown, 2012; Freed, Cann, Goff, Kuntz \& Bodner, 2005).

Associations between birds, haemosporidian parasites and dipteran vectors are governed by both biotic (e.g., host availability and density) and abiotic factors (e.g., temperature and precipitation) (Chapa-Vargas, Matta, \& Merino, 2020), as well as by anthropogenic alterations, such as deforestation and habitat degradation (Atoyan, Sargsyan, Gervorgyan, Rakovic \& Fadeev, 2018; Chasar et al., 2009; Marzal, García-longoria, \& Callirgos, 2015; Olsson-Pons, Clark, Ishtiaq, \& Clegg, 2015; Sehgal, 2010). Temperature, humidity, precipitation, 
and proximity to water appear to be the main environmental variables that influence avian-haemosporidian interactions on global and regional scales (Illera, López, García-Padilla, \& Moreno, 2017; Jones, Cheviron, \& Carling, 2013; Mendenhall, Archer, Brenes, Sekercioglu, \& Sehgal, 2013; Padilla, Illera, Gonzalez-Quevedo, Villalba, \& Richardson, 2017; Villar Couto et al., 2019). However, prevalence varies enormously between years (Bensch et al., 2007; Lachish, Knowles, Alves, Wood, \& Sheldon, 2011; Ricklefs et al., 2005) and seasons (Cosgrove, Wood, Day, \& Sheldon, 2008; Hernández-Lara, González-García, \& Santiago-Alarcón, 2017), even for climatically similar localities on smaller spatial scales (Hernández-Lara, González-García \& Santiago-Alarcón, 2017; Knowles, Wood, Alves, \& Sheldon, 2014; Wood et al., 2007). Recent work has shown that even vector communities differ between the forest canopy and the understorey (Bates, 1944; Brant et al., 2016; Chakarov, Kampen, Werner, \& Bensch, 2020; Clements, 1999), indicating that parasite transmission may differ dramatically even within a single locality. Prevalence at regional scales may thus be driven by small-scale local variation in biotic and abiotic factors.

A first step toward understanding what determines regional and ultimately global avian haemosporidian prevalence patterns is to decipher the factors governing prevalence in individual host species at local spatial scales. We address this by investigating haemosporidian prevalence, host specificity and host-parasite networks of lowland bird species in multiple forest localities in close geographic proximity in Papua New Guinea. We sampled ten abundant bird species along an east-west axis (spanning $\sim 70 \mathrm{~km}$ ) in four fragmented forest patches $(\sim 48 \mathrm{~km}$ apart) as well as five localities within a single continuous primary forest $(\sim 14 \mathrm{~km}$ apart$)$ (Figure 1). Additionally, in one locality within the continuous primary forest (Figure 1), we tested the effect of vertical stratification by comparing understorey and canopy parasite prevalence and host-parasite network structures in four confamilial species pairs.

\section{Materials and Methods}

\section{Field sites and sample collection}

All samples were collected in Madang Province of northern Papua New Guinea (PNG). In 2015 samples were collected across nine sampling sites (on an east to west axis from the coast inland), representing four small forest fragments close to human settlements (Ohu Village, Kewal Village, Yal Village, and Molum Village) and five localities within the large continuous forest of the Wanang Conservation Area (WCA) (WCA W1, WCA W2, WCA_Haus_blo_Ukiam, WCA_Nindemekin and WCA W4) (Figure 1). We focused on ten common lowland species (Arses insularis ,Ceyx solitarius , Colluricincla megarhyncha, Meliphaga analoga , Melanocharis nigra, Pitohui kirhocephalus, Rhipidura leucothorax , Symposiachrus guttula , Tanysiptera galatea, and Toxorhamphus novaeguineae ) of which a total of 273 individuals were sampled. The birds were all captured using standard mist-nets ( $\sim 3 \mathrm{~m}$ height from the ground) (Table S1).

To explore the effect of vertical stratification on avian-haemosporidian associations, we captured birds from the forest floor to $27 \mathrm{~m}$ above ground in 2013 at the Swire Station locality within WCA (Figure 1) using stacked mist-nets (for details see Chmel, Riegert, Paul, \& Novotný, 2016). After the investigation of average capture heights and removal of species for which we had less than five individuals, we identified the following four pairs of confamilial understorey and canopy species:S. guttula and Monarcha chrysomela [family: Monarchidae - Monarch flycatchers], Chalcophaphs stephani andPtilinopus magnificus [Columbidae Pigeons], M. analoga and Xanthotis flaviventer [Meliphagidae - Honeyeaters], and T. galatea and Dacelo gaudichaud[Alcedinidae - Kingfishers]) (in total, 134 individuals) (Figure S1, Table S2).

Body mass and tarsus length was measured for all individuals sampled, and a 10-20 $\mu$ l blood sample was obtained from the brachial artery and stored in $70 \%$ ethanol until DNA extraction. To test for sex-specific differences, we sexed individuals using PCRs with the primers 2550F and 2718R for Passeriformes and Columbidae, and p2 and p8 for Coraciiformes (Fridolfsson \& Ellegren, 1999). Heterogametic females and homogametic males were distinguished through visualization of PCR products on a $2 \%$ agarose gel.

\section{Molecular identification of haemosporidians}

DNA was extracted using the Qiagen DNeasyß blood and tissue kit (Hilden, Germany), following the 
manufacturer's guidelines, with a prolonged incubation period (approximately 12 hours at $56^{\circ} \mathrm{C}$ ). Haemosporidians were identified through nested PCRs with slight modifications to a well-established protocol (Bensch, Stjernman \& Hasselquist, 2000; Hellgren, Waldenström, \& Bensch, 2004). The initial PCRs were conducted in triplicates using HaemNF1 (5'-CATATATTAAGAGAAITATGGAG-3') and HaemNR3 (5'ATAGAAAGATAAGAAATACCATTC-3') primers and the PCR master mix contained a total volume of 25 $\mu$ l per sample $(12.5 \mu$ l of VWR RedTaq polymerase?, $1 \mu l$ of $10 \mathrm{mM}$ concentration of each primer and $8.5 \mu$ l of autoclaved MilliQ water and $2 \mu \mathrm{l}$ of the DNA template). These PCRs were conducted under an initial step of 3 mins at $94^{\circ} \mathrm{C}$ and 20 cycles of $30 \mathrm{~s}$ at $94^{\circ} \mathrm{C}, 30 \mathrm{~s}$ at $50^{\circ} \mathrm{C}, 45 \mathrm{~s}$ at $72^{\circ} \mathrm{C}$ and $10 \mathrm{~min}$ at $72^{\circ} \mathrm{C}$. Then, we proceeded with the second PCRs targeting specific haemosporidian genera (Haemoproteus and Plasmodium), using HaemR2 (5'-GCATTATCTGGATGTGATAATGGT-3') and HaemF (5'-ATGGTGCTTTCGATATGCATG$\left.3^{\prime}\right)$ primers. We did not investigate Leucocytozoon parasites due to their low abundance in New Guinea (Bodawatta et al., 2020). The second PCR was set up using $10 \mu$ l of Qiagen multiplex master mix (Hilden, Germany), $1 \mu \mathrm{l}$ of $10 \mathrm{mM}$ concentration of each primer and $8 \mu \mathrm{l}$ of 10x diluted product from the first PCR. The second PCR was conducted with an initial step of 3 min at $94^{\circ} \mathrm{C}$ and 35 cycles of $30 \mathrm{~s}$ at $94^{\circ} \mathrm{C}, 30 \mathrm{~s}$ at $50^{\circ} \mathrm{C}, 45 \mathrm{~s}$ at $72^{\circ} \mathrm{C}$ and $10 \mathrm{~min}$ at $72^{\circ} \mathrm{C}$. Every PCR round contained a negative control and a positive control for every 16 samples. Final PCR products were visualized in a $2 \%$ agarose gel containing GelGreen stain at $90 \mathrm{~V}$ for approximately 1 hour.

PCR products from all the positive samples were cleaned using PureIT ExoZAP PCR CleanUP (Amplicon, Odense, Denmark) and subsequently sequenced using Sanger sequencing at Eurofins Denmark (Glostrup, Denmark) for the forward primer $(\mathrm{HaemF})$. Samples with short $(<479$ base pairs $[\mathrm{bp}])$ sequences were also sequenced for the reverse primer (HaemR2). Sequences were aligned using Geneious Prime v4.8.5, and mismatches were manually checked. Aligned sequences were then compared to the MalAvi database of avian malaria parasites and related haemosporidians (Bensch, Hellgren, \& Pérez-Tris, 2009) using themalaviR v0.2.0 package in R (Ellis, Bensch, \& Canbäck, 2018). Sequences that matched reference lineages in MalAvi with less than $98 \%$ (Bensch et al. 2000, Ricklefs and Fallon 2002, Bensch et al. 2004) were considered novel lineages.

\section{Host-parasite network, lineage specificity and host phylogeny}

To explore host-parasite network structures in different sampling localities we calculated the network-level specificity index $\left(H_{2}{ }^{\prime}\right)$ for bird-haemosporidian communities using the $\mathrm{R}$ package bipartite v2.15 (Dormann, Gruber, \& Fründ, 2008). An $\mathrm{H}_{2}$ ' index close to 1 indicates specialized host-parasitic communities with more one-to-one interactions between host species and parasite lineages, while indices closer to 0 indicate more generalized networks. We also investigated haemosporidian lineage level specificity on the most common lineages (infecting $>2$ individuals) between the continuous forest and the fragmented forest patches (combining all localities within each category). We calculated specificity for each lineage using Rao's quadratic entropy, while incorporating phylogenetic distances among host species using the raoD function in the $\mathrm{R}$ package picante v1.8.2 (Kembel et al., 2010). Higher Rao's values indicate generalist lineages while lower values indicate more specialist lineages (Ellis et al., 2020).

To incorporate the host phylogeny in the calculations of Rao's quadratic entropy, we generated a host species phylogeny using a concatenated alignment of three mitochondrial (NADH dehydrogenase 2: ND2, NADH dehydrogenase 3: ND3, and Cytochrome b: cytb) and three nuclear (Myoglobin intron 2: Myo2, Glyceraldehyde-3-Phosphate Dehydrogenase intron 11: GAPDH, Ornithine decarboxylase introns 6 and 7: ODC genes, sourced from GenBank (Table S3) using BEAST v1.8.4 (Drummond, Suchard, Xie, \& Rambaut, 2012). We applied the General Time Reversible nucleotide substitution model to the concatenated dataset and ran the analysis for 100 million generations using a relaxed uncorrelated lognormal distribution for the molecular clock model, and assuming a birth-death speciation process as a tree prior. Convergence diagnostics were assessed in Tracer v1.6 (Suchard et al., 2018), by determining the effective sample sizes and mean distribution values. The final output tree was summarized in TreeAnnotator v1.8.3 (Rambaut \& Drummond, 2015) as a maximum clade credibility (MCC) tree after discarding the first 10 million generations as burn-in. 


\section{Environmental data}

Environmental variables for individual sampling localities (e.g., maximum and minimum temperature, elevation, and distance to water bodies (river and sea)) were gathered from online databases (see below). Furthermore, we collected metadata related to human activities such as vegetation type (e.g., farmlands, forests) and Normalized Difference Vegetation Index (NDVI: a proxy for forest cover) (Grace \& Gates, 1982), and distance to the closest roads for every locality. Raster layers for each variable were gathered from Diva-GIS v7.5 (https://www.diva-gis.org/Data), FreeMapTools (https://www.freemaptools.com/), Humanitarian Data Exchange v1.52.9 (https://data.humdata.org/), GeoNetwork - FAO (http://www.fao.org/geonetwork/), Copernicus Global Land Service (https://land.copernicus.eu/global/products/ndvi) and CHELSA databases (Beck et al., 2020; Karger et al., 2017; Karger, Schmatz, Dettling, \& Zimmermann, 2020). Raster layers and shapefiles were uploaded to QGIS v3.14.0 (QGIS Geographic Information System. QGIS Association., 2016) and to extract values for each locality, one vector file with the coordinates for each locality was created (Figures S2, S3). Raster layers for abiotic variables were combined with the Merge tool from the GDAL package (GDAL/GEO Contributors, 2020), and mean values of every locality from all the layers were extracted with the Point Sampling Tool Plugin v0.5.3 (Jurgiel, 2020).

NDVI was calculated using the following equation NDVI $=(\mathrm{NIR}-\mathrm{RED}) /(\mathrm{NIR}+\mathrm{RED})$, where NIR is the near-infrared and RED the visible band (Myneni, Hall, Sellers, \& Marshak, 1995). It measures the degree of absorption by chlorophyll in red wavelengths (Myneni et al., 1995), the index values fall between -1 and 1 , with values around -1 representing clouds and water, values around 0 representing bare soil and values close to 1 representing forested areas with maximum greenness (i.e., forest cover) (Atoyan et al., 2018). For environmental variables that had a low resolution for the exact GPS coordinate, we used the value of the adjacent pixel ( $<800 \mathrm{~m}$ from the original point) to that locality. We used the NNJoin Plugin v3.1.3 (Tveite, 2019), to calculate nearest neighbour relationships (Eppstein, Paterson, \& Yao, 1997) from each locality to rivers, roads and the sea (Tables S1, S4; Figures S2, S3).

\section{Statistical analyses}

Statistical analyses were conducted using R v3.6.3 (R Core Team, 2020). Haemosporidian parasites genera (Haemoproteus spp. andPlasmodium spp.) were analysed separately, using binomial (presence/absence of parasites) generalized linear models (GLMs). Due to very low prevalence $(<5 \%)$ of Plasmodium, only Haemoproteus was used in the analyses as the dependent variable in the 2015 data set (Table 1; Table S1). Furthermore, because $M$. nigra and $P$. kirhocephalus had high parasite prevalence in all localities with little to no variation (99-100\%), they were not included in GLMs (Table 1).

First, we examined the collinearity of abiotic variables using a Pearson's correlation test with the function ggpairs from the R package GGally v2.0.0 (Schloerke et al., 2019) (Figure S4). Multiple variables were significantly correlated (Figure S4). Thus, for the final analyses, we only included variables that were not collinear. Although, NDVI was positively, yet non-significantly, correlated with the vegetation type (Pearson correlation: $\mathrm{r}=0.6270, \mathrm{p}=0.1001$ ), and we chose to include NDVI rather than vegetation type due to NDVI being more accurate.

We performed both community-level and species-level models to investigate the effect of the selected variables on Haemoproteusinfections (as the dependent variable) in 2015. In the community level model, we included host species, site, sex, NDVI, distance to the roads, and minimum temperature as the independent variables. Following the guidelines in Crawley (2013), we did model selection procedures for the GLMs, and thus, variables that were not significant were eliminated from the model, resulting in a final model with considered species and NDVI as variables with significant influence. We used type-II analysis of variance (ANOVAs) from the car package v3.0.9 (Fox \& Weisberg, 2019) to obtain the $p$-values for the variables. The species-level models (separate model per species) were conducted similarly to the community-level analyses, without host species, but with sex as an independent variable. To investigate the effect of vertical stratification (data from 2013), we used separate models for Haemoproteus and Plasmodium infections with the stratum (understorey or canopy), sex and family as independent variables. 


\section{Results}

Haemosporidian prevalence and lineage diversity

Overall, 182 of the 273 bird individuals (66.6\%) were infected with haemosporidian parasites in 2015 (60.4\% with Haemoproteus and 4.4\% with Plasmodium ), while at the WCA_Swire locality in 2013, 101 of the 133 tested individuals were infected $(67.9 \%$ Haemoproteus and $7.5 \%$ Plasmodium $)$. Haemosporidian sequences (at least $479 \mathrm{bp}$ ) acquired in 2015 belonged to 43 lineages, while 37 belonging to Haemoproteus and six to Plasmodium. Of these, five Haemoproteus and two Plasmodium lineages did not match or had $<98 \%$ identity with sequences in the MalAvi database and thus considered to be new lineages. From WCA_Swire (2013) we acquired 37 unique lineages, 24 of which were Haemoproteus and seven were considered new lineages, two belonging to Plasmodium.

Due to the low prevalence of Plasmodium in the 2015 data set ( $~ 5 \%)$, GLM analyses were only conducted on Haemoproteus . Its prevalence differed significantly between host species (binomial GLM: $L R \chi^{2}=58.08$, $\mathrm{df}=8, \mathrm{p}<0.0001$; Figure S5) and close to be significant between sites (binomial GLM: $L R \chi^{2}=15.06$, $\mathrm{df}=8, \mathrm{p}=0.0579$, when considering both parasite genera: binomial GLM: $L R \chi^{2}=17.13, \mathrm{df}=8, \mathrm{p}=$ 0.0287; for overall Haemosporidian prevalence, see Figure S6), suggesting that some bird species are more susceptible to infections, and that localities differ in prevalence levels. Furthermore, prevalence did not differ between sexes (binomial GLM: $L R \chi^{2}=0.8358, \mathrm{df}=1, \mathrm{p}=0.3606$ ). The strong host species effect supports conducting statistical analyses on both host community and species levels.

More specialized host-parasite networks in localities within the continuous forest

Host-parasite network structure was more specialized than expected by chance throughout continuous forest localities $\left(\mathrm{H}_{2}{ }^{\prime}=0.7691\right.$, null mean 1,000 random iterations: $0.6537, \mathrm{p}=0.0013$; Figure $\left.2 \mathrm{~A}\right)$, while network structures of fragmented forests depicted more random associations $\left(\mathrm{H}_{2}{ }^{\prime}=0.6074\right.$, null mean $\mathrm{m}_{1,000}$ random iterations: $0.5774, \mathrm{p}=0.3158$; Figure 2B). This was consistent across individual localities, except for two within the continuous forest (Figures S7, S8). This indicates that avian-haemosporidian networks within the undisturbed forests are more specialized than those of fragmented forests. The host specificity of lineages that infected more than two individual hosts demonstrated a significant positive association with their abundance in fragmented forests $\left(\mathrm{lm}: \mathrm{F}=13.58, \mathrm{R}^{2}=0.6113, \mathrm{p}=0.0078\right)$, but not in continuous forest $(\mathrm{lm}: \mathrm{F}=3.456$, $\mathrm{R}^{2}=0.2144, \mathrm{p}=0.1001$ ) (Figure $2 \mathrm{C}$ ).

Species-specific effects of abiotic factors on Haemoproteus

prevalence between localities

Despite the significant effect of locality on Haemoproteusprevalence, there was no significant difference between continuous and fragmented forests (binomial GLM: $L R \chi^{2}=0.8737$, df $=1, \mathrm{p}=0.3499$; Figure S9). We found 27 unique haemosporidian haplotypes in the forest fragments and 26 in the continuous forest (Figure S10). At the bird community level, NDVI was the only significant predictor of Haemoproteus prevalence, which decreased with increasing NDVI (binomial GLM: $L R \chi^{2}=6.2816, \mathrm{df}=1, \mathrm{p}=0.0122$, Figure S11). However, species-level analyses (Table 1) revealed significant effects of several predictors on Haemoproteus prevalence, but effects were host species-specific (Table 1, Figure 3). Increased NDVI affected Haemoproteus prevalence negatively for all species except in $R$. leucothorax; yet the association was only significant for $T$. galatea and M. analoga (Table 1, Figure 3). On the other hand, C. solitarius, R. leucothorax and M. analoga bore higher Haemoproteus prevalence the closer they were to roads (Table 1, Figure 3). Minimum temperature negatively affected parasite prevalence for all species except for $C$. megarhyncha ; however, this was only significant for $A$. insularis (Table 1, Figure 3).

\section{Prevalence levels of haemosporidian genera differed by strata}

We found significant differences in the overall prevalence of two haemosporidian genera between canopy $(88.8 \%)$ and understorey $(74.2 \%)$ hosts (Figure 4A). Haemoproteus infections were significantly greater in the canopy $(80.5 \%)$ compared to the understorey (52.6\%) (binomial GLM: $L R \chi^{2}=9.178$, df $=1$, p 
$=0.0020$, Figure 4A), while Plasmodium prevalence, although overall low, was higher in the understorey $(21.6 \%)$ than in the canopy $\left(8.3 \%\right.$ ), with nearly significant differences (binomial GLM: $L R \chi^{2}=3.479$, df $=1, \mathrm{p}=0.0621$, Figure 4A). Bird families were similarly infected between strata (binomial GLM: $L R \chi^{2}$ $=3.568, \mathrm{df}=1, \mathrm{p}=0.3198$ ) and so were different sexes (binomial GLM: $L R \chi^{2}=1.1407, \mathrm{df}=1, \mathrm{p}=$ 0.5653). There were 23 unique haplotypes in the understorey and 14 in the canopy, of which 17 and 12 of those, respectively, wereHaemoproteus . Only seven lineages were shared between strata (Figure S12). Host-parasite network structures of four understorey $\left(\mathrm{H}_{2}{ }^{\prime}=0.8322\right.$, null mean ${ }_{1,000}$ random iterations: 0.7470 , $\mathrm{p}=0.1441)$ and canopy $\left(\mathrm{H}_{2}{ }^{\prime}=0.8402\right.$, null mean ${ }_{1,000}$ random iterations: $\left.0.7655, \mathrm{p}=0.1775\right)$ species revealed high network level specialisation $\left(\mathrm{H}_{2}{ }^{\prime}\right)$, however, these did not differ significantly from random expectations (Figures S13A, S13B). Interestingly, there were more specialist lineages (when considering lineages in $>$ two individuals) in the understorey than the canopy (Figure S13C), suggesting that the high prevalence observed in the canopy might be a result of the presence of more generalist lineages (Figure 4).

\section{Discussion}

We investigated the influence of environmental and anthropogenic factors on haemosporidian (Haemoproteus and Plasmodium ) parasite prevalence, distribution, specificity, and host-parasite network structures in tropical lowland birds at horizontal and vertical spatial scales (Figures 2 and 4). Haemoproteus was the most common parasite genus, aligning with previous work in New Guinea (Bodawatta et al., 2020), who sampled at a site less than $25 \mathrm{~km}$ from our study sites. However, Haemoproteus prevalence was overall markedly lower in the previous study ( $15 \%$ ). The lowland study site sampled by Bodawatta et al. (2020) represents the lowest part of the Mount Wilhelm montane gradient and includes the total bird community, while our localities are part of an extensive lowland area and only include ten abundant bird species. Topographical differences and sampled avian communities of the two localities may thus at least in part explain the observed prevalence-level differences.

At the bird community level, NDVI (forest cover) was the only variable that appeared to reduce prevalence significantly. However, at the species level, the picture is less clear, with species-specific effects of minimum temperature, distance to roads and NDVI on Haemoproteus infections (Figure 3). Further, we found vertical segregation in host-parasite interactions with higher prevalence in the canopy than in the understorey. Haemoproteus accounted for the majority of infections in both strata, but with a higher relative proportion in the canopy (Figure 4). Collectively, this suggests that specific vector communities may influence the transmission of particular malarial strains but also that adaptation to particular ecological niches of host species makes them differentially exposed to pathogens.

More specialized host-parasite networks in undisturbed forests

We did not find significant differences in Haemoproteusprevalence between the localities within the continuous forest and the fragmented forests, which aligns with results from regional spatial scale studies in the Neotropics and the Afrotropics (Belo, Pinheiro, Reis, Ricklefs, \& Braga, 2011; Chasar et al., 2009; Loiseau et al., 2010; Rivero de Aguilar et al., 2018; Sebaio, Braga, Branquinho, Fecchio, \& Marini, 2012). However, our findings contrast a study from tropical Australia which found higher Haemoproteus prevalence in continuous than fragmented forest (Laurance et al., 2013). Higher prevalence levels in continuous forest have been speculated to be a result of higher vector abundances (Zhou, Munga, Minakawa, Githeko \& Yan, 2007; Mangudo, Aparicio, Rossi \& Gleiser, 2017). Thus, forest structure could indirectly affect parasite infection risk through influencing the vector abundances (Zhou et al. 2007; Mangudo et al. 2017), implying that vector sampling across forest types is needed to decipher their potential effects on prevalence levels between continuous and fragmented forests.

While prevalences did not differ between the continuous and fragmented forest, host-parasite network structures were notably different, where continuous forest harboured significantly more specialized networks (Figure 2A) than fragmented forests (Figure 2B). The greater specialization in continuous forest could imply that undisturbed forests may provide more stable environments with higher host species richness (Bregman, Sekercioglu, \& Tobias, 2014; Sam, Koane, Jeppy, \& Novotny, 2014) that could lead to more specialized 
associations. Highly specialized avian-haemosporidian networks has been observed before in an undisturbed tropical lowland bird community in Ecuador (Svensson-Coelho, Ellis, Loiselle, Blake, \& Ricklefs, 2014). Fragmented forests, on the other hand, tend to favour generalist parasite lineages (driving observed random host-parasite network structures), which is evident by the observed association between host specificity of lineages and their abundances in the fragmented but not in the continuous forest (Figure 2C). This aligns with the niche-breadth hypothesis (Ellis et al., 2020; Pinheiro et al., 2016), which predicts that generalists parasite lineages with broader host niches perform better in small forest patches than specialist lineages. The differences in lineage specificity and abundances in fragmented versus continuous forests may thus result from $i$ ) changes in bird communities (abundances and densities) (Bodawatta et al., 2020; Fecchio, Bell, et al., 2019; Fecchio, Wells, et al., 2019), ii ) changes in the potential for competition between haemosporidian lineages (Bodawatta et al., 2020) and/or iii) changes in environmental variables associated with forest fragmentation (Afrane, Zhou, Lawson, Githeko, \& Yan, 2006).

Haemosporidian prevalence levels depict species-specific responses to environmental and anthropogenic factors

Of the tested environmental variables, only increased NDVI (forest cover) led to significantly reduced Haemoproteus prevalence, suggesting that minimum temperature and distance to roads do not significantly affect community-level haemosporidian prevalence at local spatial scales. NDVI appears to be a good predictor for vector abundance and distribution (Roiz, Ruiz, Soriguer, \& Figuerola, 2015) and has been shown to be - in contrast to our own findings - positively associated with Haemoproteus prevalence in seasonal temperate regions (Clark, Drovetski, \& Voelker, 2020). However, our tropical localities had very high (0.8 to 1.0) NDVI with minor differences between sites, compared to studies in temperate regions (Fecchio et al., 2020; Ferraguti et al., 2018; Roiz et al., 2015). Thus, our results are not directly comparable with studies conducted in temperate regions but open the possibility of a non-linear relationship between NDVI and parasite prevalence. Further, these indicate a need for researching the effect of NDVI on Haemoproteus vector (i.e., biting midges) communities in tropical lowlands. We note that NDVI is significantly correlated with elevation above sea-level and vegetation type, suggesting that the observed results could also be due to a combination of factors that are correlated with NDVI.

The species-specific effect of different environmental variables onHaemoproteus prevalence (Figure 2) aligns with results from other studies on bird species from both temperate and tropical regions (Isaksson, Sepil, Baramidze, \& Sheldon, 2013; Samuel, Woodworth, Atkinson, Hart, \& LaPointe, 2015; Santiago-Alarcon et al., 2019; Van Hoesel, Santiago-Alarcon, Marzal, \& Renner, 2020). Despite the overall non-significant effect of distance to the road (a proxy for anthropogenic influence) on prevalence, this factor did significantly affect prevalence in three bird species, suggesting the potential for elevated infection levels with increased anthropogenic activity (Table 1). The influence of anthropogenic activity on haemosporidian prevalence and their vectors has been documented for multiple bird species across geographical localities, showing either positive (Abella-Medrano, Ibáñez-Bernal, MacGregor-Fors, \& Santiago-Alarcon, 2015), negative (Chasar et al., 2009b; Gonzalez-Quevedo, Davies, \& Richardson, 2014), or no (Sehgal, 2015) effects. This is consistent with our findings, as the magnitude of anthropogenic activity effects on prevalence differ from bird species to species (Figure 3).

Temperature tends to positively impact haemosporidian prevalence at regional scale in both tropical and temperate regions (Chapa-Vargas et al., 2020; Padilla, Illera, Gonzalez-Quevedo, Villalba, \& Richardson, 2017; Sehgal, 2015; Zamora-Vilchis, Williams, \& Johnson, 2012). However, we found that increased minimum temperature (even minor differences, ${ }^{\sim} 1.5^{\circ} \mathrm{C}$ ) had a negative effect on Haemoproteus prevalence across multiple species (albeit only significantly for A. insularis ) (Figure 2). Consensus of the effect of temperature on parasite prevalence in birds in the Australo-Papuan region is lacking, as studies have shown positive (Zamora-Vilchis et al., 2012) or no (Bodawatta et al., 2020) effects. Areas with lower temperatures experience more rainfall in our study region (Figure S4), indicating potentially more vector breeding habitats (Lapointe, Atkinson, \& Samuel, 2012; Sehgal, 2015) and the consequent abundance increase in localities with lower temperatures, which could lead to increased prevalence. In summary, our findings imply that the sum of species-specific responses to different environmental variables dictate community-level effects of abiotic 
factors in tropical bird communities.

Higher prevalence and reduced diversity of haemosporidians in the canopy

Higher Haemoproteus prevalence in the canopy with a lower prevalence in the understorey (Figure 4) aligns with previous findings from the Afrotropics (Lutz et al., 2015). However, Plasmodiumprevalence was higher in the understorey compared to the canopy, which may reflect higher mosquito abundances (Plasmodium vectors) at the forest floor. Nonetheless, our finding suggests that the pattern might be opposite for biting midges vectors of Haemoproteus that are conceivably higher in the canopy as they tend to prefer higher forest heights better than ground strata (Černý, Votýpka, \& Svobodová, 2011; Garvin \& Greiner, 2003; Swanson \& Adler, 2010; Swanson, Adler, \& Malmqvist, 2012). Only five of the 32 haemosporidian lineages were shared between the two strata, likely due to vertical segregation of vector species (Henry \& Adkins, 1975), implying that investigations of both canopy and understorey bird communities in a locality is needed to fully characterise host-vector-parasite diversity and associations.

\section{Conclusions}

Our results demonstrate that interactions between haemosporidian parasites and tropical avian hosts are influenced by a multitude of factors at different taxonomic levels and spatial scales. Forest structure influences associations between particular host species and parasite lineages, while parasite prevalence of a set of host species (the community) is driven by a combination of species-specific environmental effects. Vertical separation within a single locality appears to expose avian hosts to markedly different parasite pressures, which is likely driven by vector communities. Taken together, these results emphasize the importance of investigating avian-haemosporidian associations in space, for individual host species and at the host community level. Finally, the species-specific effects of environmental variables and vertical stratification on parasite prevalence accentuate that the factors driving these interactions can differ between global, regional and local spatial scales.

\section{Data accessibility}

New haemosporidian sequences will be deposited in GenBank and MalAvi. Complete data sets utilized in this study are given in Supplementary tables S1, S2, S3 and S4.

\section{Competing interest statement}

All the authors declare there is not competing interest related to material of this manuscript.

\section{Author Contributions}

CVI, KHB, MP, KAJ developed the idea. KC and LP conducted the field work. CVI and KHB conducted the molecular work. CVI, NB, JR-H and PM analysed the data. CVI wrote the first draft of the manuscript and all authors contributed to the revision of the manuscript.

\section{Acknowledgments}

We thank the Carlsberg Foundation for a Distinguished Associate Professor Fellowship to K. A. J. (CF170248), the Villum Foundation for a Young Investigator Grant to K.A.J. (project no. 15560) and The Grant Agency of the Czech Republic (GACR 19-28126X and GAJU 037/2016/P) and The Darwin Initiative (DIR25S1 $\backslash 100123)$ grant to KC for funding this project. We also thank the New Guinea Binatang Research Centre for enabling us to conduct the field work.

\section{References}

Abella-Medrano, C. A., Ibáñez-Bernal, S., MacGregor-Fors, I., \& Santiago-Alarcon, D. (2015). Spatiotemporal variation of mosquito diversity (Diptera: Culicidae) at places with different land-use types within a neotropical montane cloud forest matrix. Parasites and Vectors , 8 (1). doi: 10.1186/s13071-015-1086-9

Afrane, Y. A., Zhou, G., Lawson, B. W., Githeko, A. K., \& Yan, G. (2006). Effects of microclimatic changes caused by deforestation on the survivorship and reproductive fitness of Anopheles gambiae in western Kenya 
highlands. The American journal of tropical medicine and hygiene, 74 (5), 772-778.

Atkinson, C. T. (2009). Avian Malaria. In Parasitic Diseases of Wild Birds (pp. 35-53). Wiley-Blackwell. doi: 10.1002/9780813804620.ch3

Atoyan, H. A., Sargsyan, M., Gevorgyan, H., Raković, M., Fadeev, I., Muradyan, V., ... Aghayan, S. A. (2018). Determinants of avian malaria prevalence in mountainous Transcaucasia. Biologia ,73 (11), 1123-1130. doi: 10.2478/s11756-018-0128-0

Bates, M. (1944). Observations on the Distribution of Diurnal Mosquitoes in a Tropical Forest. Ecology , 25 (2), 159-170. doi: $10.2307 / 1930689$

Beck, H. E., Wood, E. F., McVicar, T. R., Zambrano-Bigiarini, M., Alvarez-Garreton, C., Baez-Villanueva, O. M., ... Karger, D. N. (2020). Bias correction of global high-resolution precipitation climatologies using streamflow observations from 9372 catchments.Journal of Climate, 33 (4), 1299-1315. doi: 10.1175/JCLID-19-0332.1

Belo, N. O., Pinheiro, R. T., Reis, E. S., Ricklefs, R. E., \& Braga, É. M. (2011). Prevalence and lineage diversity of avian haemosporidians from three distinct cerrado habitats in Brazil. PloS One ,6 (3), e17654. doi: 10.1371/journal.pone.0017654

Bensch, Staffan, \& Hellgren, O. (2020). The Use of Molecular Methods in Studies of Avian Haemosporidians. In Avian Malaria and Related Parasites in the Tropics (pp. 113-135). Springer International Publishing. doi: 10.1007/978-3-030-51633-8_4

Bensch, Staffan, Waldenström, J., Jonzán, N., Westerdahl, H., Hansson, B., Sejberg, D., \& Hasselquist, D. (2007). Temporal Dynamics and Diversity of Avian Malaria Parasites in a Single Host Species.Source: Journal of Animal Ecology , 76 (1), 112-122. doi: 10.1111/j

Bensch, Stffan, Stjernman, M., Hasselquist, D., Örjan, Ö., Hannson, B., Westerdahl, H., \& Pinheiro, R. T. (2000). Host specificity in avian blood parasites: a study of Plasmodium and Haemoproteusmitochondrial DNA amplified from birds. Proceedings of the Royal Society of London. Series B: Biological Sciences , 267 (1452), 1583-1589. doi: 10.1098/rspb.2000.1181

Bodawatta, K. H., Synek, P., Bos, N., Garcia-del-Rey, E., Koane, B., Marki, P. Z., . . Jønsson, K. A. (2020). Spatiotemporal patterns of avian host-parasite interactions in the face of biogeographical range expansions. Molecular Ecology , 29 (13), 2431-2448. doi: 10.1111/mec.15486

Brant, H. L., Ewers, R. M., Vythilingam, I., Drakeley, C., Benedick, S., \& Mumford, J. D. (2016). Vertical stratification of adult mosquitoes (Diptera: Culicidae) within a tropical rainforest in Sabah, Malaysia.Malaria Journal , 15 (1), 370. doi: 10.1186/s12936-016-1416-1

Bregman, T. P., Sekercioglu, C. H., \& Tobias, J. A. (2014). Global patterns and predictors of bird species responses to forest fragmentation: Implications for ecosystem function and conservation.Biological Conservation , 169 , 372-383. doi: 10.1016/j.biocon.2013.11.024

Černý, O., Votýpka, J., \& Svobodová, M. (2011). Spatial feeding preferences of ornithophilic mosquitoes, blackflies and biting midges. Medical and Veterinary Entomology , 25 (1), 104-108. doi: 10.1111/j.13652915.2010.00875.x

Chakarov, N., Kampen, H., Werner, D., \& Bensch, S. (2020). Blood parasites in vectors reveal a united blacky community in the upper canopy. Parasites $\&$ Vectors , 13 (309). doi: 10.21203/rs.2.22636/v3

Chapa-Vargas, L., Matta, N. E., \& Merino, S. (2020). Effects of Ecological Gradients on Tropical Avian Hemoparasites. In Avian Malaria and Related Parasites in the Tropics (pp. 349-377). Springer International Publishing. doi: 10.1007/978-3-030-51633-8_10

Chasar, A., Loiseau, C., Valkiūnas, G., Iezhova, T., Smith, T. B., \& Sehgal, R. N. M. (2009a). Prevalence and diversity patterns of avian blood parasites in degraded African rainforest habitats. Molecular Ecology, 
18 (19), 4121-4133. doi: 10.1111/j.1365-294X.2009.04346.x

Clark, NJ, Drovetski, SV, Voelker, G. Robust geographical determinants of infection prevalence and a contrasting latitudinal diversity gradient for haemosporidian parasites in Western Palearctic birds.Molecular Ecology . 2020; 29: 3131-3143. doi:10.1111/mec.15545

Clements, A. N. (1999). Biology of Mosquitoes. Volume 2, Sensory Reception and Behaviour. UK: CABI Publishing.

Cosgrove, C. L., Wood, M. J., Day, K. P., \& Sheldon, B. C. (2008). Seasonal variation in Plasmodium prevalence in a population of blue tits Cyanistes caeruleus. Journal of Animal Ecology , 77 (3), 540-548. doi: $10.1111 / \mathrm{j} .1365-2656.2008 .01370 . \mathrm{x}$

Crawley, M. J. (2013). The R Book. Chichester, West Sussex, United Kingdom:Wiley.

Dormann, C. F., Gruber, B., \& Fründ, J. (2008). Introducing the bipartite Package: Analysing Ecological Networks. Inbiom.uni-freiburg.de (Vol. 8). Retrieved from http://erzuli.ss.uci.edu/R.stuff.

Drummond, A. J., Suchard, M. A., Xie, D., \& Rambaut, A. (2012). Bayesian phylogenetics with BEAUti and the BEAST 1.7. Molecular Biology and Evolution, 29 (8), 1969-1973. doi: 10.1093/molbev/mss075

Ellis, V. A., Huang, X., Westerdahl, H., Jönsson, J., Hasselquist, D., Neto, J. M., ... Bensch, S. (2020). Explaining prevalence, diversity and host specificity in a community of avian haemosporidian parasites. Oikos , 129 (9), 1314-1329. doi: 10.1111/oik.07280

Eppstein, D., Paterson, M. S., \& Yao, F. F. (1997). On nearest-neighbor graphs. Discrete and Computational Geometry , 17 (3), 263-282. doi: 10.1007/PL00009293

Ewen, J. G., Bensch, S., Blackburn, T. M., Bonneaud, C., Brown, R., Cassey, P., .. Pérez-Tris, J. (2012). Establishment of exotic parasites: the origins and characteristics of an avian malaria community in an isolated island avifauna. Ecology Letters , 15 (10), 1112-1119.

Fecchio, A., Bell, J. A., Bosholn, M., Vaughan, J. A., Tkach, V. V., Lutz, H. L., .. Clark, N. J. (2020). An inverse latitudinal gradient in infection probability and phylogenetic diversity for Leucocytozoon blood parasites in New World birds. Journal of Animal Ecology , 89 (2), 423-435. doi: 10.1111/1365-2656.13117

Fecchio, A., Bell, J. A., Pinheiro, R. B. P., Cueto, V. R., Gorosito, C. A., Lutz, H. L., .. Collins, M. D. (2019). Avian host composition, local speciation and dispersal drive the regional assembly of avian malaria parasites in South American birds. Molecular Ecology ,28 (10), 2681-2693. doi: 10.1111/mec.15094

Fecchio, A., Wells, K., Bell, J. A., Tkach, V. V., Lutz, H. L., Weckstein, J. D., .. Clark, N. J. (2019). Climate variation influences host specificity in avian malaria parasites. Ecology Letters , 22 (3), 547-557. doi: $10.1111 /$ ele. 13215

Ferraguti, M., Martínez-de la Puente, J., Bensch, S., Roiz, D., Ruiz, S., Viana, D. S., .. Figuerola, J. (2018). Ecological determinants of avian malaria infections: An integrative analysis at landscape, mosquito and vertebrate community levels. Journal of Animal Ecology , 87 (3), 727-740. doi: 10.1111/1365-2656.12805

Fox, J., \& Weisberg, S. (2019). An R Copmanion to Applied Regression (Third). Retrieved from https://cran.r-project.org/web/packages/car/citation.html

Freed, L. A., Cann, R. L., Goff, M. L., Kuntz, W. A., Bodner, R., \& Bodner, G. R. (2005). Increase in Avian Malaria at Upper Elevation in Hawai'i. The Condor , 107 (4), 753-764.

Fridolfsson, A.-K., \& Ellegren, H. (1999). A Simple and Universal Method for Molecular Sexing of Non-Ratite Birds. In Source: Journal of Avian Biology (Vol. 30). Retrieved from https://www.jstor.org/stable/3677252

García del Río, M., Castaño-Vázquez, F., \& Merino, S. (2020). Effects of climate change on bird-parasite interactions. Ecosistemas ,29 (2). doi: 10.7818/ECOS.1981 
Garvin, M. C., \& Greiner, E. C. (2003). Epizootiology of Haemoproteus Danilwskyi (Haemosporina: Haemoproteidae) in Blue Jays (Cyanocitta cristata) in Southcentral Florida. Source: Journal of Wildlife Diseases , 39 (1), 1-9. doi: 10.7589/0090-3558-39.1.1

Gonzalez-Quevedo, C., Davies, R. G., \& Richardson, D. S. (2014). Predictors of malaria infection in a wild bird population: Landscape-level analyses reveal climatic and anthropogenic factors. Journal of Animal Ecology , 83 (5), 1091-1102. doi: 10.1111/1365-2656.12214

Grace, J., \& Gates, D. M. (1982). Biophysical Ecology. In The Journal of Ecology (Vol. 70). doi: $10.2307 / 2259893$

Hellgren, O., Pérez-Tris, J., \& Bensch, S. (2009). A jack-of-all-trades and still a master of some: prevalence and host range in avian malaria and related blood parasites. Ecology , 90 , 2840-2849. doi: 10.1890/08-1059.1

Hellgren, O., Waldenström, J., \& Bensch, S. (2004). a New Pcr Assay for Simultaneous Studies of Leucocytozoon, Plasmodium, and Haemoproteus From Avian Blood. Journal of Parasitology , 90 (4), 797-802. doi: $10.1645 /$ ge-184r1

Henry, L. G., \& Adkins, T. R. (1975). Vertical Distribution of Biting Midges in Coastal South Carolina. Annals of the Entomological Society of America , 68 (2), 321-324. doi: 10.1093/aesa/68.2.321

Hernández-Lara, C., González-García, F., \& Santiago-Alarcon, D. (2017). Spatial and seasonal variation of avian malaria infections in five different land use types within a Neotropical montane forest matrix.Landscape and Urban Planning , 157 , 151-160. doi: 10.1016/J.LANDURBPLAN.2016.05.025

Illera, J. C., López, G., García-Padilla, L., \& Moreno, Á. (2017). Factors governing the prevalence and richness of avian haemosporidian communities within and between temperate mountains. PloS One ,12 (9), e0184587. doi: 10.1371/journal.pone.0184587

Isaksson, C., Sepil, I., Baramidze, V., \& Sheldon, B. C. (2013). Explaining variance of avian malaria infection in the wild: The importance of host density, habitat, individual life-history and oxidative stress. BMC Ecology , 13 . doi: 10.1186/1472-6785-13-15

Jones, M. R., Cheviron, Z. A., \& Carling, M. D. (2013). Spatial Patterns of Avian Malaria Prevalence in Zonotrichia capensis on the Western Slope of the Peruvian Andes . Journal of Parasitology ,99 (5), 903-905. doi: $10.1645 / 12-147.1$

Jurgiel, B. (2020). Point Sampling Tool - QGIS Python Plugins Repository . Retrieved from https://plugins.qgis.org/plugins/pointsamplingtool/

Karger, D. N., Conrad, O., Böhner, J., Kawohl, T., Kreft, H., Soria-Auza, R. W., ... Kessler, M. (2017). Climatologies at high resolution for the earth's land surface areas. Scientific Data ,4 . doi: 10.1038/sdata.2017.122

Karger, D. N., Schmatz, D. R., Dettling, G., \& Zimmermann, N. E. (2020). High-resolution monthly precipitation and temperature time series from 2006 to 2100. Scientific Data , 7 (1). doi: 10.1038/s41597-020-00587-y

Kembel, S. W., Cowan, P. D., Helmus, M. R., Cornwell, W. K., Morlon, H., Ackerly, D. D., .. Webb, C. O. (2010). Picante: R tools for integrating phylogenies and ecology. Bioinformatics ,26 (11), 1463-1464. doi: 10.1093/bioinformatics/btq166

Knowles, S. C. L., Wood, M. J., Alves, R., \& Sheldon, B. C. (2014). Dispersal in a patchy landscape reveals contrasting determinants of infection in a wild avian malaria system. Journal of Animal Ecology , 83 (2), 429-439. doi: 10.1111/1365-2656.12154

Lachish, S., Knowles, S. C. L., Alves, R., Wood, M. J., \& Sheldon, B. C. (2011). Infection dynamics of endemic malaria in a wild bird population: Parasite species-dependent drivers of spatial and temporal variation in transmission rates. Journal of Animal Ecology ,80 (6), 1207-1216. doi: 10.1111/j.1365-2656.2011.01893.x 
Lapointe, D. A., Atkinson, C. T., \& Samuel, M. D. (2012). Ecology and conservation biology of avian malaria. Annals of the New York Academy of Sciences , 1249 (1), 211-226. doi: 10.1111/j.1749-6632.2011.06431.x

Loiseau, C., Iezhova, T., Valkiūnas, G., Chasar, A., Hutchinson, A., Buermann, W., .. Sehgal, R. N. M. (2010). Spatial Variation of Haemosporidian Parasite Infection in African Rainforest Bird Species. Journal of Parasitology , 96 (1), 21-29. doi: 10.1645/ge-2123.1

Lutz, H. L., Hochachka, W. M., Engel, J. I., Bell, J. A., Tkach, V. V., Bates, J. M., ... Weckstein, J. D. (2015). Parasite prevalence corresponds to host life history in a diverse assemblage of afrotropical birds and haemosporidian parasites. PLoS ONE , 10 (4). doi: 10.1371/journal.pone.0121254

Marzal, A., García-longoria, L., \& Callirgos, J. M. C. (2015).Invasive avian malaria as an emerging parasitic disease in native birds of Peru . (May). doi: 10.1007/s10530-014-0718-x

Mendenhall, C. D., Archer, H. M., Brenes, F. O., Sekercioglu, C. H., \& Sehgal, R. N. M. (2013). Balancing biodiversity with agriculture: Land sharing mitigates avian malaria prevalence. Conservation Letters ,6 (2), 125-131. doi: 10.1111/j.1755-263X.2012.00302.x

R. B. Myneni, F. G. Hall, P. J. Sellers and A. L. Marshak, The interpretation of spectral vegetation indexes. IEEE Transactions on Geoscience and Remote Sensing, vol. 33, no. 2, pp. 481-486, March 1995, doi: 10.1109/TGRS.1995.8746029.

Olsson-Pons, S., Clark, N. J., Ishtiaq, F., \& Clegg, S. M. (2015). Differences in host species relationships and biogeographic influences produce contrasting patterns of prevalence, community composition and genetic structure in two genera of avian malaria parasites in southern Melanesia. Journal of Animal Ecology , 84 (4), 985-998. doi: 10.1111/1365-2656.12354

Padilla, D. P., Illera, J. C., Gonzalez-Quevedo, C., Villalba, M., \& Richardson, D. S. (2017a). Factors affecting the distribution of haemosporidian parasites within an oceanic island. International Journal for Parasitology , 47 (4), 225-235. doi: 10.1016/j.ijpara.2016.11.008

Pinheiro, R. B. P., Félix, G. M. F., Chaves, A. V., Lacorte, G. A., Santos, F. R., Braga, É. M., \& Mello, M. A. R. (2016). Trade-offs and resource breadth processes as drivers of performance and specificity in a host-parasite system: A new integrative hypothesis.International Journal for Parasitology , 46 (2), 115-121. doi: 10.1016/j.ijpara.2015.10.002

Poulin, R. (1998). Evolutionary Ecology Of Parasites . London: Chapman \& Hall.

Poulin, Robert. (1999). The functional importance of parasites in animal communities: Many roles at many levels? International Journal for Parasitology , 29 (6), 903-914. doi: 10.1016/S0020-7519(99)00045-4

QGIS Geographic Information System. QGIS Association. (2016).QGIS.org • Retrieved from https://www.qgis.org

RC Team. (2020). R: A Language and Environment for statistical computing. In pbil.univ-lyon1.fr . doi: 10.1016/j.dendro.2008.01.002

Ricklefs, R. E., Swanson, B. L., Fallon, S. M., MartÍnez-AbraÍn, A., Scheuerlein, A., Gray, J., \& Latta, S. C. (2005). Community Relationships Of Avian Malaria Parasites In Southern Missouri.Ecological Monographs , 75 (4), 543-559. doi: 10.1890/04-1820

Rivero, A., \& Gandon, S. (2018). Evolutionary Ecology of Avian Malaria: Past to Present. Trends in Parasitology , 34 (8), 712-726. doi: 10.1016/j.pt.2018.06.002

Rivero de Aguilar, J., Castillo, F., Moreno, A., Peñafiel, N., Browne, L., Walter, S. T., ... Bonaccorso, E. (2018). Patterns of avian haemosporidian infections vary with time, but not habitat, in a fragmented Neotropical landscape. PLOS ONE , 13 (10), e0206493. doi: 10.1371/journal.pone.0206493 
Roiz, D., Ruiz, S., Soriguer, R., \& Figuerola, J. (2015). Landscape Effects on the Presence, Abundance and Diversity of Mosquitoes in Mediterranean Wetlands. PLoS ONE , 10 (6), 128112. doi: 10.1371/journal.pone.0128112

Sam, K., Koane, B., Jeppy, S., \& Novotny, V. (2014). Effect of forest fragmentation on bird species richness in Papua New Guinea.Journal of Field Ornithology , 85 (2), 152-167. doi: 10.1111/jofo.12057

Samuel, M. D., Woodworth, B. L., Atkinson, C. T., Hart, P. J., \& LaPointe, D. A. (2015). Avian malaria in Hawaiian forest birds: Infection and population impacts across species and elevations.Ecosphere , 6 (6), 1-21. doi: 10.1890/ES14-00393.1

Santiago-Alarcon, D., MacGregor-Fors, I., Falfán, I., Lüdtke, B., Segelbacher, G., Schaefer, H. M., \& Renner, S. (2019). Parasites in space and time: a case study of haemosporidian spatiotemporal prevalence in urban birds. International Journal for Parasitology ,49 (3-4). doi: 10.1016/j.ijpara.2018.08.009

Schloerke, B., Cook, D., Larmarange, J., Briatte, F., Marbach, M., Thoen, E., .. Wickham, H. (2019, March 8). GGally: Extension to ggplot2 . Comprehensive R Archive Network (CRAN). Retrieved from https://cran.r-project.org/package=GGally, https://ggobi.github.io/ggally/

Sebaio, F., Braga, É. M., Branquinho, F., Fecchio, A., \& Marini, M. Â. (2012). Blood parasites in passerine birds from the Brazilian Atlantic Forest. Revista Brasileira de Parasitologia Veterinaria ,21 (1), 7-15. doi: 10.1590/s1984-29612012000100003

Sehgal, R. N. M. (2010). Deforestation and avian infectious diseases. Journal of Experimental Biology , 213 (6), 955-960. doi: 10.1242/jeb.037663

Sehgal, Ravinder N.M. (2015). Manifold habitat effects on the prevalence and diversity of avian blood parasites. International Journal for Parasitology: Parasites and Wildlife , 4 (3), 421-430. doi: 10.1016/j.ijppaw.2015.09.001

Soares, L., Latta, S. C., \& Ricklefs, R. E. (2017). Dynamics of avian haemosporidian assemblages through millennial time scales inferred from insular biotas of the West Indies. Proceedings of the National Academy of Sciences , 114 (25), 6635-6640. doi: 10.1073/pnas.1702512114

Suchard, M. A., Lemey, P., Baele, G., Ayres, D. L., Drummond, A. J., \& Rambaut, A. (2018). Bayesian phylogenetic and phylodynamic data integration using BEAST 1.10. Virus Evolution , 4 (1). doi: 10.1093/ve/vey016

Svensson-Coelho, M., Ellis, V. A., Loiselle, B. A., Blake, J. G., \& Ricklefs, R. E. (2014). Reciprocal Specialization in Multihost Malaria Parasite Communities of Birds: A Temperate-Tropical Comparison. The American Naturalist , 184 (5), 624-635. doi: 10.1086/678126

Swanson, D. A., \& Adler, P. H. (2010). Vertical distribution of haematophagous Diptera in temperate forests of the southeastern U.S.A.Medical and Veterinary Entomology , 24 (2), 182-188. doi: 10.1111/j.13652915.2010.00862.x

Swanson, D. A., Adler, P. H., \& Malmqvist, B. (2012). Spatial stratification of host-seeking Diptera in boreal forests of northern Europe. Medical and Veterinary Entomology , 26 (1), 56-62. doi: 10.1111/j.13652915.2011.00963.x

TreeAnnotator | BEAST Documentation. (n.d.). Retrieved March 2, 2021, from https://beast.community/treeannotator

Tveite, H. (2019). The QGIS NNJoin Plugin - NNJoin 3.1 .3 documentation . Retrieved from

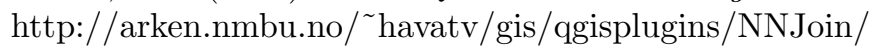

Valkiūnas, G. (2005). Avian malaria parasites and other haemosporidia. In Igarss 2014. doi: 10.1007/s13398-014-0173-7.2 
Van Hoesel, W., Santiago-Alarcon, D., Marzal, A., \& Renner, S. C. (2020). Effects of forest structure on the interaction between avian hosts, dipteran vectors and haemosporidian parasites. BMC Ecology, 20 (1), 1-13. doi: 10.1186/s12898-020-00315-5

Villar Couto, C. M., Cumming, G. S., Lacorte, G. A., Congrains, C., Izbicki, R., Braga, E. M., .. Del Lama, S. N. (2019). Avian haemosporidians in the cattle egret (Bubulcus ibis) from central-western and southern Africa: High diversity and prevalence. PLoS ONE ,14 (2), 1-16. doi: 10.1371/journal.pone.0212425

Wood, M. J., Cosgrove, C. L., Wilkin, T. A., Knowles, S. C. L., Day, K. P., \& Sheldon, B. C. (2007). Within-population variation in prevalence and lineage distribution of avian malaria in blue tits, Cyanistes caeruleus. Molecular Ecology , 16 , 3263-3273.

Zamora-Vilchis, I., Williams, S. E., \& Johnson, C. N. (2012). Environmental temperature affects prevalence of blood parasites of birds on an elevation gradient: Implications for disease in a warming climate.PLoS ONE , 7 (6). doi: 10.1371/journal.pone.0039208

\section{Figures}

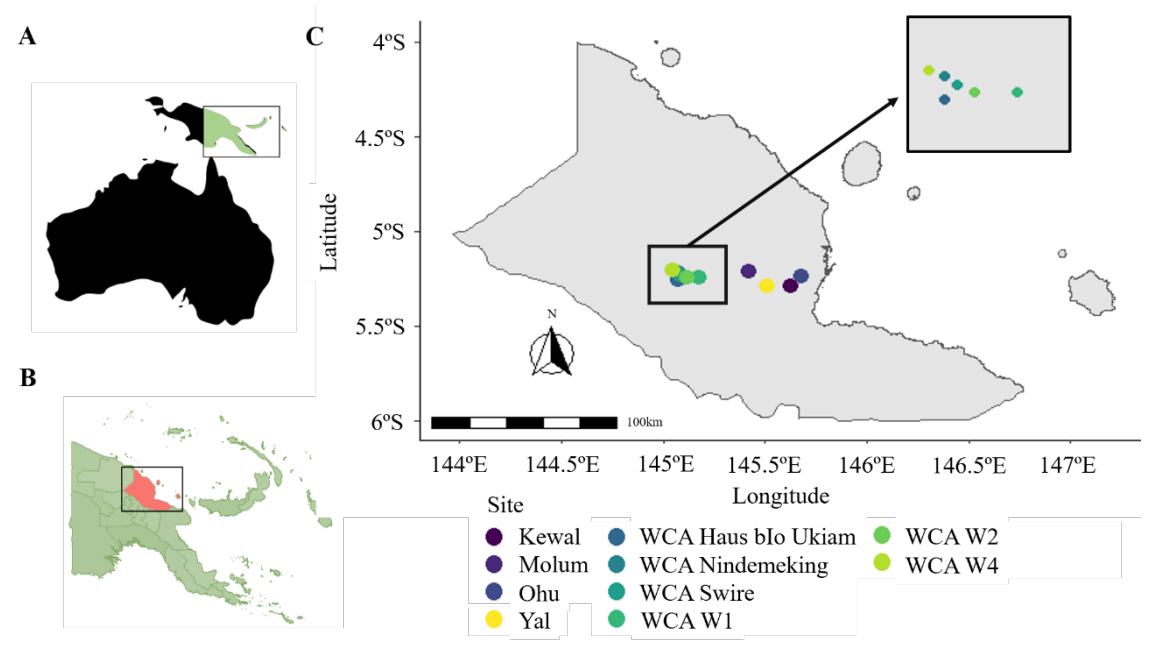

Figure 1. Map depicting (A ) the location of Papua New Guinea (PNG) in Oceania, and (B) the location of Madang province in Northern PNG. C . Map of the Madang province indicating the ten sampling sites (9 in 2015 and 1 in 2013) located on an east to west axis. Code names starting with WCA are within the continuous Wanang Conservation Area. The WCA Swire locality was only sampled in 2013. 
A

Localities withing Wanang forest: Observed $\mathrm{H}_{2}{ }^{\prime}=0.7691$ (null mean $\mathrm{H}_{2}{ }^{\prime}=0.6537, \mathrm{p}=0.0013^{*}$ )

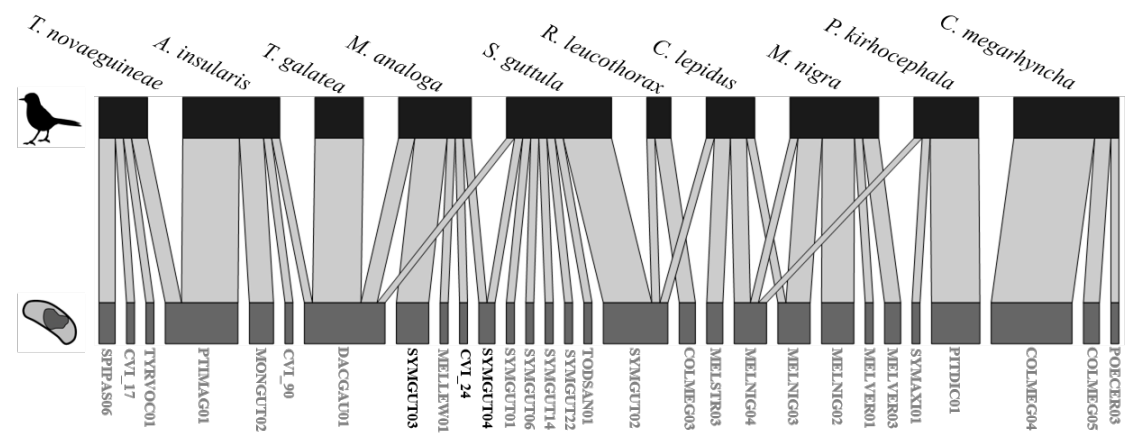

B

Fragmented forest patches: Observed $\mathrm{H}_{\mathbf{2}}{ }^{\prime}=\mathbf{0 . 6 0 7 4}\left(\right.$ null mean $\mathrm{H}_{\mathbf{2}}{ }^{\prime}=0.5774, \mathrm{p}=\mathbf{0 . 3 1 5 8}$ )

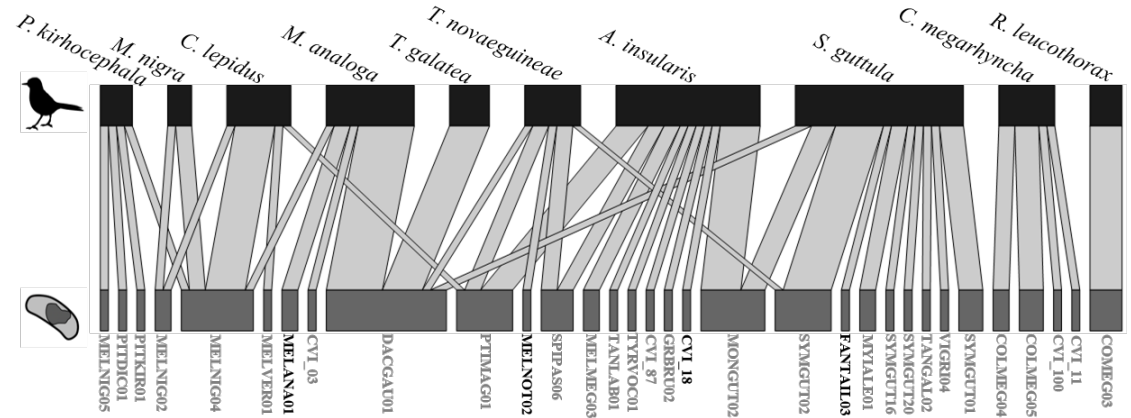

C

Localities withing Wanang forest

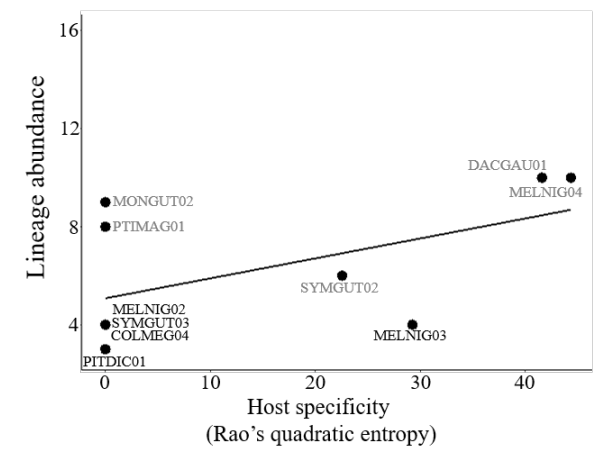

Lowland forest patches

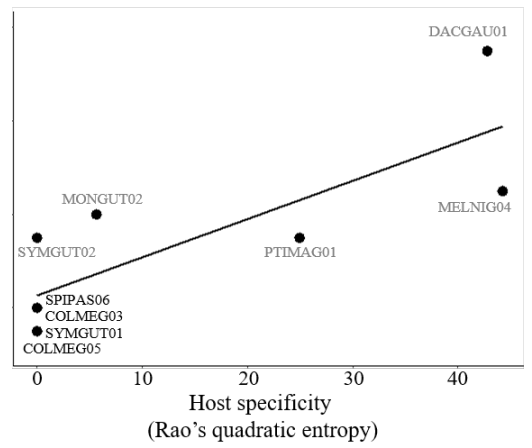

Figure 2. Bird-haemosporidian networks and host specificity in different forest categories (continuous vs. fragmented). Networks indicate combined host-parasite communities of the five localities within Wanang Conservation Area (A ) and four fragmented forest patches (B ). An $\mathrm{H}_{2}$ ' index closer to 1 indicates that host-parasitic communities are more specialized (many one-to-one associations), while highly generalized networks have $\mathrm{H}_{2}$ ' indices closer to 0 . Observed $\mathrm{H}_{2}$ ' and the average $\mathrm{H}_{2}$ ' acquired from 1,000 null models are given within parentheses. Observed $\mathrm{H}_{2}$ ' values significantly different from the null expectation is indicated with an asterisk. Haemoproteus lineage names in grey andPlasmodium lineage names in black. C . Association between host specificity of the most abundant haemosporidian lineages (Rao's quadratic entropy) and the lineage abundance in the continuous forest and fragmented forests. Parasite lineages found in both forest categories are given in grey. Large Rao values indicate generalist lineages while small values indicate specialist lineages. Host specificity was only calculated for parasite lineages that infected more than two bird individuals. 

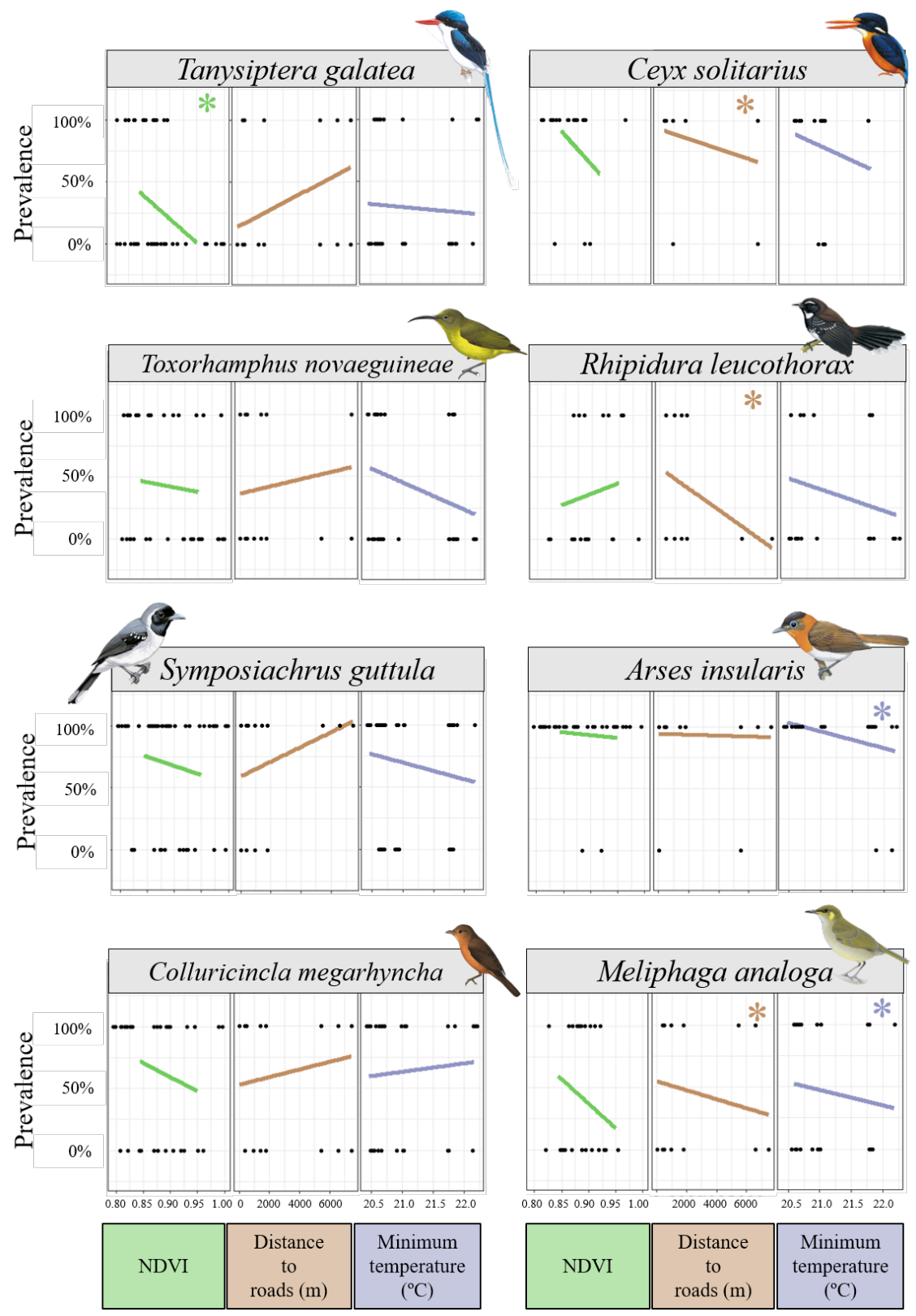

Figure 3. Associations of Haemoproteus prevalence with minimum temperature $\left({ }^{\circ} \mathrm{C}\right)$, distance to roads (m) and NDVI across all sampling sites for all species sampled in 2015. Pitohui kirhocephalus and Melanocharis nigra were not included in these analyses as all individuals were infected. Dots represent infected (100\%) or non-infected (0\%) individuals and lines (linear model estimates) show the prevalence changes associated with each variable. Significant effects from the GLMs are indicated with asterisks. Bird drawings were acquired from the Handbook of the Birds of the World (del Hoyo et al. 2018). 


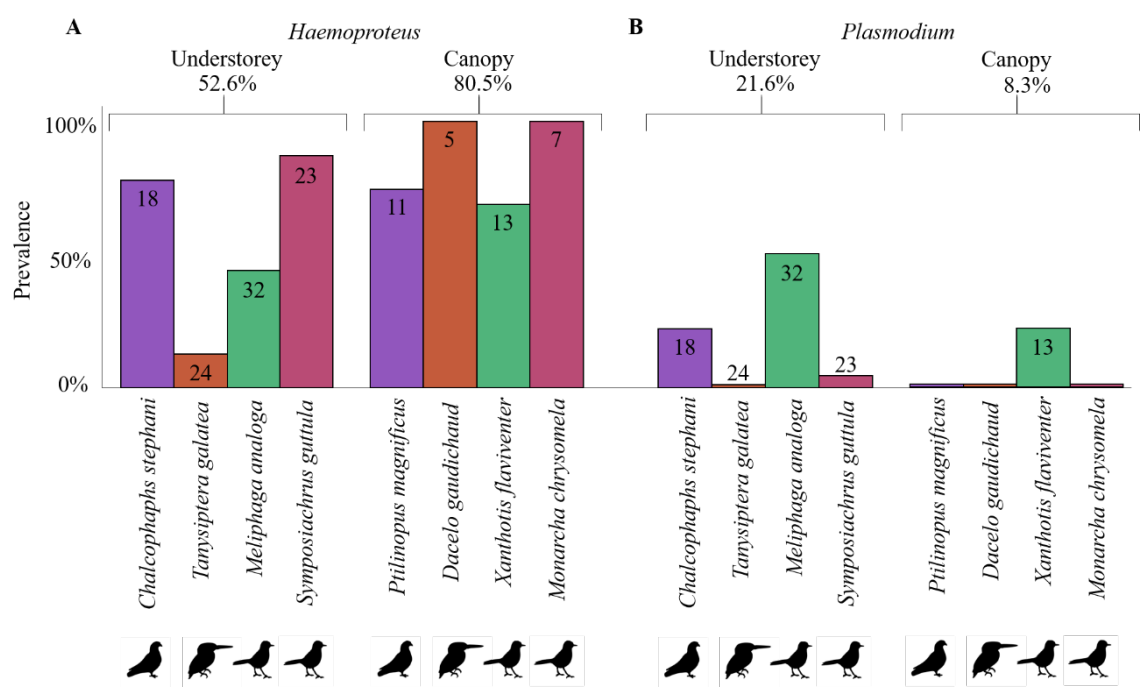

Figure 4. Haemosporidian prevalence of canopy and understorey species. Box plots depict mean overall prevalence of (A ) Haemoproteusand (B ) Plasmodium ( \pm SD) across the species sampled in the canopy and in the understorey at the WCA_Swire site in 2013. The number of samples is indicated at the top of the bars. Confamilial pairs are indicated with identical colours and silhouettes.

Table with legend

Table 1. Species-level effects based on binomial GLM analyses of abiotic variables (NDVI and minimum temperature) and distance to roads (proxy for anthropogenic disturbance) on Haemoproteus prevalence in 2015. Significant effects are marked with an asterisk $\left(^{*}\right)$.

\begin{tabular}{|c|c|c|c|c|c|}
\hline Species & Dependent variable & Independent variable & $L R \chi^{2}$ & $d f$ & $\operatorname{Pr}\left(>\chi^{2}\right)$ \\
\hline \multirow[t]{3}{*}{ Arses insularis } & Haemoproteus & NDVI & 1 & 1 & 1 \\
\hline & & Minimum temperature & 6.279 & 1 & $0.0122^{*}$ \\
\hline & & Distance to roads & -0 & 1 & 1 \\
\hline \multirow[t]{3}{*}{ Ceyx solitarius } & Haemoproteus & NDVI & 3.587 & 1 & 0.0582 \\
\hline & & Minimum temperature & 1.694 & 1 & 0.1930 \\
\hline & & Distance to roads & 3.984 & 1 & $0.0459^{*}$ \\
\hline \multirow[t]{3}{*}{ Tanysiptera galatea } & Haemoproteus & NDVI & 3.995 & 1 & $0.0456^{*}$ \\
\hline & & Minimum temperature & 0.8908 & 1 & 0.3453 \\
\hline & & Distance to roads & 1.563 & 1 & 0.2112 \\
\hline \multirow[t]{3}{*}{ Toxoramphus novaeguineae } & Haemoproteus & NDVI & 0.2827 & 1 & 0.5950 \\
\hline & & Minimum temperature & 2.291 & 1 & 0.1302 \\
\hline & & Distance to roads & 0.3801 & 1 & 0.5376 \\
\hline \multirow[t]{3}{*}{ Rhipidura leucothorax } & Haemoproteus & NDVI & 1.562 & 1 & 0.2113 \\
\hline & & Minimum temperature & 1.548 & 1 & 0.2135 \\
\hline & & Distance to roads & 6.2813 & 1 & $0.0122^{*}$ \\
\hline \multirow[t]{3}{*}{ Symposiachrus guttula } & Haemoproteus & NDVI & 0.1047 & 1 & 0.7462 \\
\hline & & Minimum temperature & 0.1353 & 1 & 0.7130 \\
\hline & & Distance to roads & 3.265 & 1 & 0.0708 \\
\hline \multirow[t]{3}{*}{ Colluricincla megarhyncha } & Haemoproteus & NDVI & 0.4502 & 1 & 0.5022 \\
\hline & & Minimum temperature & 0.0978 & 1 & 0.7545 \\
\hline & & Distance to roads & 0.1434 & 1 & 0.7050 \\
\hline Meliphaga analoga & Haemoproteus & NDVI & 6.432 & 1 & $0.0112^{*}$ \\
\hline
\end{tabular}




\begin{tabular}{|c|c|c|c|c|c|}
\hline$\overline{\text { Species }}$ & Dependent variable & Independent variable & $L R \chi^{2}$ & $d f$ & $\operatorname{Pr}\left(>\chi^{2}\right)$ \\
\hline & & Minimum temperature & 1.802 & 1 & 0.1794 \\
\hline & & Distance to roads & 4.949 & 1 & $0.0261^{*}$ \\
\hline
\end{tabular}

\section{Captions for Supplementary tables and figures}

Supplementary figure legends

Figure S1. Box plots depict mean heights ( \pm SD) of captured individuals of eight bird species included in the vertical stratification analyses. Understorey species tend to occupy larger stratum ranges than canopy species. Mean heights of understorey species are below $15 \mathrm{~m}$ above ground while the mean heights of canopy species are above $\sim 18 \mathrm{~m}$.

Figure S2. GIS raster layers and localities from lowland PNG.(A) Roads (purple lines) and localities, (B) distances to rivers and streams (green lines) and (C) elevation in lowland PNG. Darker colours in figure $\mathrm{C}$ indicate lower elevations. Images extracted from QGIS v3.14.0. Values for each locality in supplementary table C.

Figure S3. GIS raster layers and localities from lowland PNG.(A) Maximum temperature, (B) minimum temperature and $(\mathrm{C})$ precipitation. Darker colours in every figure indicate higher values. Images extracted from QGIS v3.14.0).

Figure S4. Correlation plot showing the results for Pearson's correlation test on abiotic variables that are relevant for haemosporidian prevalence distribution. Significant results are marked with an asterisk $(*)$.

Figure S5. TotalHaemoproteus prevalence (\%) per species in 2015 . Numbers of sampled individuals (n) are shown inside the bars.

Figure S6. Haemoproteus prevalence (\%) in the different localities sampled in 2015. Numbers of sampled individuals (n) are shown inside the bars. Localities are ordered by distance to the sea; closest to the right and furthest to the left.

Figure S7. Bird-haemosporidian networks in each of the localities within the continuous Wanang forest. Observed $\mathrm{H}_{2}$ ' and the average $\mathrm{H}_{2}$ ' acquired from 1,000 null models are given within parenthesis. Significantly different $\mathrm{H}_{2}{ }^{\prime}$ compared to expected by chance are indicated with asterisks. Bird species names in black, Haemoproteus lineage names in grey, and Plasmodium lineage names in red. An H2' index closer to 1 indicates that host-parasitic communities are more specialized (many one-to-one associations), while highly generalized networks have $\mathrm{H} 2$ ' indices closer to 0 .

Figure S8. Bird-haemosporidian networks in different lowland forest fragments. Observed network-level specificity index (H2') and the average $\mathrm{H} 2$ ' from 1,000 null models are given within parentheses. Bird species names in black, Haemoproteus lineage names in grey, and Plasmodium lineage names in red. An H2' index close to 1 indicates that host-parasite communities are more specialized (many one-to-one associations), while highly generalized networks have $\mathrm{H} 2$ ' indices closer to 0 .

Figure S9. Box plots depict mean prevalences (+- SD) of bird species from 2015 in the fragmented forest and the Wanang area (continuous forest). Dots indicate individual observations of prevalence by species and numbers inside the boxplots are the mean prevalence values. Prevalence did not significantly differ between continuous and fragmented forest.

Figure S10. Parasite lineages found in the continuous forest (all the localities within Wanang Conservation Area) and the fragmented forest (all the fragmented forests). Dots indicate the presence of a parasite lineage in a species. 
Figure S11. Associations of Haemoproteus prevalence NDVI across all sampling sites sampled in 2015. Dots represent infected $(100 \%)$ or non-infected (0\%) individuals and lines (linear model) show the prevalence change associated NDVI.

Figure S12. Parasite lineages found in the canopy and the understorey. Dots indicate the presence of a parasite lineage in a species.

Figure S13. Host-parasite network structures and the haemosporidian lineage level specificity in canopy and understorey bird species at Wanang 3. A) Four canopy bird species and B) four understorey bird species from corresponding families were investigated in this analysis. Observed network specificity index (H2') and the average H2' from 1,000 null models are given within parentheses. Bird species names in black, Haemoproteus lineage names in grey, andPlasmodium lineage names in red. An H2' index closer to 1 indicates that host-parasitic communities are more specialized (many one-to-one associations), while highly generalized networks have H2' indices closer to 0 . Asterisks represent haemosporidian lineages found in both canopy and understorey species. C) Rao's quadratic entropy (Host specificity of lineages) of most frequent parasite lineages (for lineages that have infected more than two bird individuals) demonstrated more specialist lineages in the understorey compared to the canopy.

Supplementary Table legends

Table S1. Dataset corresponding to sampling in 2015. Infection status of ten different species sampled in nine different localities within a continuous and a fragmented forest with information about biometrics.

Table S2. Dataset corresponding to sampling in 2013. Infection status of the four confamilial pairs of species sampled in WCA in 2013 with information about biometrics.

Table S3. GenBank accessions for three nuclear and three mitochondrial genes used to construct the host phylogeny.

Table S4. Table with all the environmental variables for each locality sampled in 2015. Data from precipitation, temperature, elevation, vegetation type, NDVI, distance to the sea, river, city and roads. Vegetation type is indicated as (1) broadleaved evergreen or semi-deciduous closed to open trees (2) rainfed croplands or (3) cultivated and managed terrestrial areas(s)/ natural and semi-natural primarily terrestrial. 